\title{
A Comparative Study of Seismic Performance of the Building Designed using Four Major Codes
}

\author{
Mohammad Azim Eirgash \\ Ph.D Candidate \\ Karadeniz Technical University \\ Department of Civil Engineering \\ Turkey Trabzon. 61000
}

\begin{abstract}
As the size of the buildings increases, the complexity in analyzing it rises and the use of software packages become inevitable. Therefore, needs to high rise buildings are felt to be indispensable. In this study, an example of 20 - story structure building is modeled as a case study, then using some software packages, the model which gave sufficient ductility, drift and rebar percentage were considered as the most efficient as well as conservative model. Project planning involves two important objectives. The first objective is to perform the analysis and design of the present high rise building using STAAD Pro Vi8 as well as ETABS v17. The building will be analyzed for different load combinations according to the relevant Indian standard codes. The second objective of this study is to analyze the seismic performance and design the above-mentioned structure using seismic code provisions of Europe, New Zealand, USA, and India. The stability of the structure under such diverse environments is studied and analyzed. The obtained result indicates that the IS 1893-2002 requires the maximum rebar percentage for the chosen beam and column among the utilized codes, hence is the most conservative as well as uneconomical code of practice to adopt, whereas ASCE 318M-02 requires smaller story drift and more specifically, more secure than the other implemented codes.
\end{abstract}

Keywords - Seismic Performance, Drift Estimation, High rise building, Software package.

\section{INTRODUCTION}

In the past few years, building codes define different ductility classes and specify corresponding response reduction factors based on the material, configuration, and detailing. All modern national seismic design codes converge on the issue of design methodology. These are based on a prescriptive force-based design approach, where the design is performed using a linear elastic analysis, and inelastic energy dissipation is considered indirectly, through a response reduction factor (or behavior factor). This factor, along with other interrelated provisions, governs the seismic design forces and hence the seismic performance of code-designed buildings. However, different national codes vary significantly on account of various specifications which govern the design force level. The response reduction factor, as considered in the design codes, depends on the ductility of the structure. Building codes define different ductility classes and specify corresponding response reduction factors based on the structural material, configuration and detailing. Another important issue, which governs the design and expected seismic performance of a building, is control of drift. Drift is recognized as an important control parameter by all the codes; however, they differ regarding the effective stiffness of RC members. Further, the procedures to estimate drift and the allowable limits on drift also vary considerably. Different codes differ not only with respect to the design base shear but also employ different load and material factors (or strength reduction factors) for the design of members, and hence, the actually provided strength in different codes does not follow the same pattern as the design base shear. This has direct effect on the expected performance of buildings designed using different codes. Further, the other provisions of codes also indirectly govern the seismic performance. In the area of globalization, there is a need for convergence of design methodologies to result in buildings with uniform risk of suffering a certain level of damage or collapse. A first step in this direction is to compare the expected seismic performance of buildings designed using the provisions of different codes. The provisions of different codes regarding effective stiffness of RC members, procedure to estimate drift, and allowable drift limits are also compared to each other. Codes also differ significantly in specifying the effective stiffness of RC members, procedures to estimate drift, and allowable limits on drift. Avadhoot et al (2018) evaluates the seismic risk of selected vertically irregular buildings in terms of their fragility curves, annual probability of collapse, drift hazard curves, and confidence levels and correlates seismic risk with the corresponding degree of irregularity using different existing irregularity indicators. The results presented in this paper show that the existing irregularity indicators do not correlate with the associated seismic risk of vertically irregular buildings. This paper will help architects and engineers to choose appropriate building configuration without compromising their seismic safety.

Mohaiminul Haque et al (2016) studied regular frame and setback frame structure of different shape such as W, L, square shape etc. and found that the storey displacement of setback frame was high as compared to regular frame structure. Zaid Mohammad et al. (2016) he analyzed the hill building via response spectrum method and result found in terms of shear forces induced in the columns at foundation level, fundamental time periods, storey drifts and storey shear in buildings, maximum top storey displacements and compared with the considered configurations of hilly region buildings.

In the present study, it is set out to prepare a comparative study of different ductility classes and corresponding response reduction factors, reinforcement detailing provisions, and a case study of seismic performance of a RC building designed using four major codes, viz. ASCE-7 (United States), EN1998-1 (Europe), NZS 1170.5 (New Zealand) and IS 1893 (India). 
The presentation of this study is as follows: basic explanations for the storey drift is elaborated first. Subsequently, descriptions for reinforcement bar is going to be presented followed by geometrical configuration. To demonstrate the seismic analysis and rebar percentage, software analysis are then examined and finally, numerical results are given along with concluding remarks and the conclusion.

\section{STOREY DRIFT}

An earthquake principally causes movement of the ground and hence a base displacement rather than a surface force like wind. As the ground moves in one direction, the building base attached to it slides in the direction of movement, while the structure above the ground lags behind because the inertia of the building mass resists movement. The amount of horizontal displacement of any point in the building relative to the ground is called drift. Drift causes stress in structural and non-structural elements because it causes distortion. Because earthquake movement is a reversed cyclic motion, vibration is induced in the building and a wave of distortion travels along the height of the building. Maximum drift usually takes place at the top of a building, but each story level is subjected to a certain amount of drift known as interstory drift, which is calculated as the difference between the lateral displacements of one floor and the one below as shown.

\subsection{EFFECT ON STRUCTURAL INTEGRITY}

Many observations and dynamic-response studies have shown that a building's collapse potential is greatly affected by the amount of drift (Naeim, 1989). In the absence of deformation compatibility, lateral displacement can affect both elements of the lateral force resisting system and gravity load bearing elements, by causing too much distortion, leading to premature failure and loss of strength (Freeman et al., 2004). Also excessive drift can affect the vertical stability of a building, especially flexible massive buildings, potentially leading to collapse due to $\mathrm{P}-\Delta$ effects.

\subsection{EFFECT ON ARCHITECTURAL ELEMENTS}

If non-structural elements, for example partitions, glass and cladding systems, are not well isolated from the movements of the structural elements, they may get damaged as a result of drift and fall off jeopardizing safety of occupants and requiring high repair costs. Also staircase enclosures tend to inhibit inter-story drift resulting in damage. Moreover, the non-structural elements may interfere with their attached structural elements and lead to some undesirable results for example creating short columns, torsion, or stiffness irregularities.

\subsection{CONTROL OF DRIFT}

Performance of structural as well as non-structural components of a building is controlled by inter-story drift. Inter story drift also governs the secondary $(P-\Delta)$ effects and it is one of the most important design parameters, and governs the member sizes in many cases, particularly in the case of tall buildings. As in the case of design base shear, the various codes differ not only in the limits on inter story drift, but also in the estimation procedure. In ASCE 7, elastic displacement at a floor level is calculated and amplified by a deflection amplification factor depending on the type of building. Limits are provided on amplified inter story drifts, representing the inelastic deformations in the building. Eurocode 8 presents limits on the elastic displacements amplified directly by the behavior factor. NZS 1170.5 requires the elastic displacements to be multiplied by the structural ductility factor and drift modification factor in order to obtain inelastic displacements. The drift modification factor accounts for higher mode effects and depends on the height of the building. IS 1893 provides the drift control limits directly on the elastic displacement at the design load, without any amplification for ductility demand. ASCE 7 limits story drift according to occupancy category and allows up to $2.5 \%$ drift for ordinary multistory RC frame buildings. According to Eurocode 8, the allowable story drift depends on the type of non-structural elements, and for multistory RC framed buildings, the allowable drift is $1 \%$ for buildings having brittle non-structural elements, $1.5 \%$ for buildings having ductile non-structural elements, and $2 \%$ for buildings having non-structural elements which are fixed in a way so as not to interfere with structural deformations or without nonstructural elements. NZS 1170.5 allows a story drift of $2.5 \%$ for all types of buildings, irrespective of material and occupancy class. Considering the ductility factor approximately to be equal to the response reduction factor, the effective limits at ultimate displacement are $1.2 \%$ and $2 \%$ for OMRF and SMRF, respectively. Consideration of the effective stiffness of RC members is obviously the most crucial step in the estimation of building deformations and inter story drifts. ACI $318 \mathrm{M}-08$ specifies effective stiffness as $70 \%$ and $35 \%$ of the gross stiffness for columns and beams, respectively. Eurocode 8 specifies $50 \%$ of gross stiffness as the effective stiffness for both columns and beams, while NZS 3101:Part1 suggests the effective stiffness for rectangular beams to be $32 \%$ and $40 \%$ of the gross section stiffness for yield strength $(f y)$ of reinforcement equal to 500 $M P a$ and $300 \mathrm{MPa}$, respectively. The corresponding values for columns vary from 0.40 to 0.80 with a reinforcement ratio for $f y=300 \mathrm{MPa}$, and from 0.30 to 0.80 for $f y=500 \mathrm{MPa}$. In addition to the code provisions, several other proposals for the effective stiffness of RC members under seismic loads are available which vary significantly. Therefore, in addition to the design base shear, a consensus on the limits and estimation procedure for permissible drift is also necessary for uniformity in expected performance and associated risk, in buildings designed as per different codes. This is also crucial for the development of future versions of seismic codes based on displacement-based design methodology.

\section{REINFORCEMENT BAR}

Rebar (short for reinforcing bar), also known as reinforcing steel and reinforcement steel is a common steel bar or mesh of steel wires commonly used as a tension device in reinforced concrete and reinforced masonry structures to strengthen and hold the concrete in compression. The surface of the rebar may be patterned to form a better bond with the concrete. 


\subsection{USE IN CONCRETE AND MASONRY}

Concrete is a material that is very strong in compression, but relatively weak in tension. To compensate for this imbalance in concrete's behaviour, rebar is cast into it to carry the tensile loads. Most steel reinforcement is conceptually divided into primary and secondary reinforcement, but there are other minor uses: Primary reinforcement refers to the steel which is employed specifically to guarantee the necessary resistance needed by the structure as a whole to support the design loads. Secondary reinforcement, also known as distribution or thermal reinforcement, is employed for durability and aesthetic reasons, by providing enough localized resistance to limit cracking and resist stresses caused by effects such as temperature changes and shrinkage. It is also employed to confer resistance to concentrated loads by providing enough localized resistance and stiffness for a load to spread through a wider area. Rebar may also be used to hold other steel bars in the correct position to accommodate their loads.

\section{GEOMETRICAL CONFIGURATION}

A plan of $\mathrm{G}+22$ reinforced concrete (RC) frame structure is considered for modeling and analysis using some software packages. Beam sizes: $230 \times 500 \mathrm{~mm}$ (M25 for Beams). Typical RC column sizes of $300 * 900$ at the two parking levels and for the bottom five levels. This gradually shifted to $300 * 750$ for the next 5 floors, $300 * 600$ for the next 5 and finally $300 * 450$ for the top 5 floors. Grade of concrete used for columns -> M50 at base level and gradually reduced to M25 at the top levels. The thickness of external wall is $200 \mathrm{~mm}$ and internal wall is $100 \mathrm{~mm}$ have taken and the floor finish load $1 \mathrm{kN} / \mathrm{m}^{2}$ and roof treatment load $1.5 \mathrm{kN} / \mathrm{m}^{2}$. Table 1 demonstrates the material and geometric specifications of the structure.

TABLE 1. MATERIAL AND GEOMETRIC SPECIFICATIONS OF THE STRUCTURE

\begin{tabular}{|c|c|}
\hline Material & $\mathrm{M} 25 / \mathrm{Fe} 500$ \\
\hline The number of floors & 22 \\
\hline Typical RC column sizes & $300 \times 900$ \\
\hline Beam sizes: & $230 \times 500 \mathrm{~mm}$ \\
\hline Slab thickness & $\mathrm{h}_{\mathrm{f}}=150 \mathrm{~mm}$ \\
\hline Earthquake zone & $1^{\text {st }}$ degree \\
\hline Building importance factor & $\mathrm{I}=1.5$ \\
\hline Live load contribution factor & $\mathrm{n}_{\mathrm{k}}=0.6$ \\
\hline Live load coefficient & $\mathrm{q}=2 \mathrm{k} \mathrm{N} / \mathrm{m}^{2}$ \\
\hline Effective ground acceleration coefficient & $\mathrm{A}_{0}=0.40$ \\
\hline Local site class & $\mathrm{Z} 2$ \\
\hline Structural behavior factor & $\mathrm{R}=6$ \\
\hline Story Height & $3.2 \mathrm{~m}$ \\
\hline Floor Finish Load & $1.25 \mathrm{kN} / \mathrm{m} 2$ \\
\hline
\end{tabular}

\section{DESCRIPTION OF THE TEST STRUCTURE}

The structural analysis is performed using the STAAD Pro software which is based on finite element analysis technique, it also includes the modules for generation and application of earthquake loads, subsequent code checking of structural elements and joints and capabilities to carry-out static analysis. Figures 1 and 2 exhibit the plan and 3D view of the building drawn in Revit Architecture.

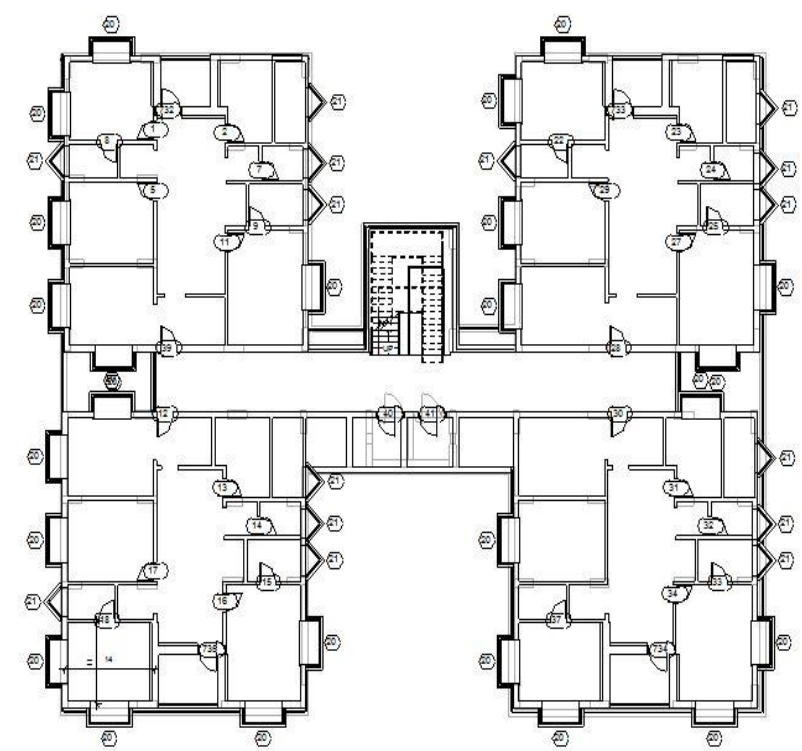

FIG. 1. PLAN OF THE BUILDING DRAWN IN REVIT ARCHITECTURE.

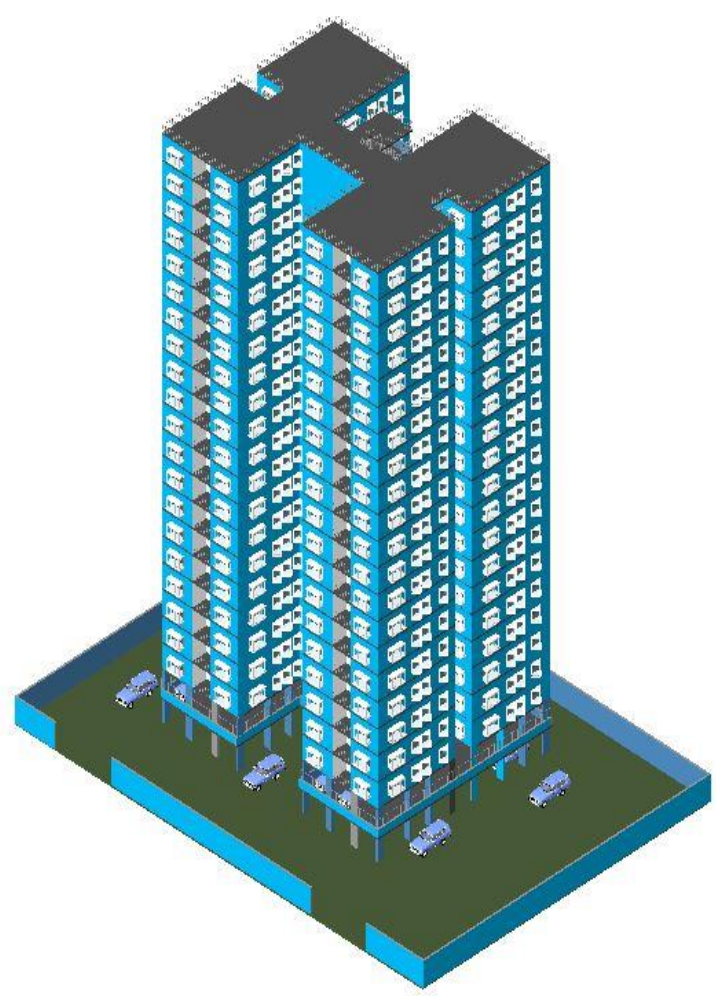

FIG.2. 3D DRAWING OF THE BUILDING USING REVIT ARCHITECTURE

\section{RESULTS}

The result of typical beam behaviour obtained by Etabs as well as Staad Pro is drawn below. 


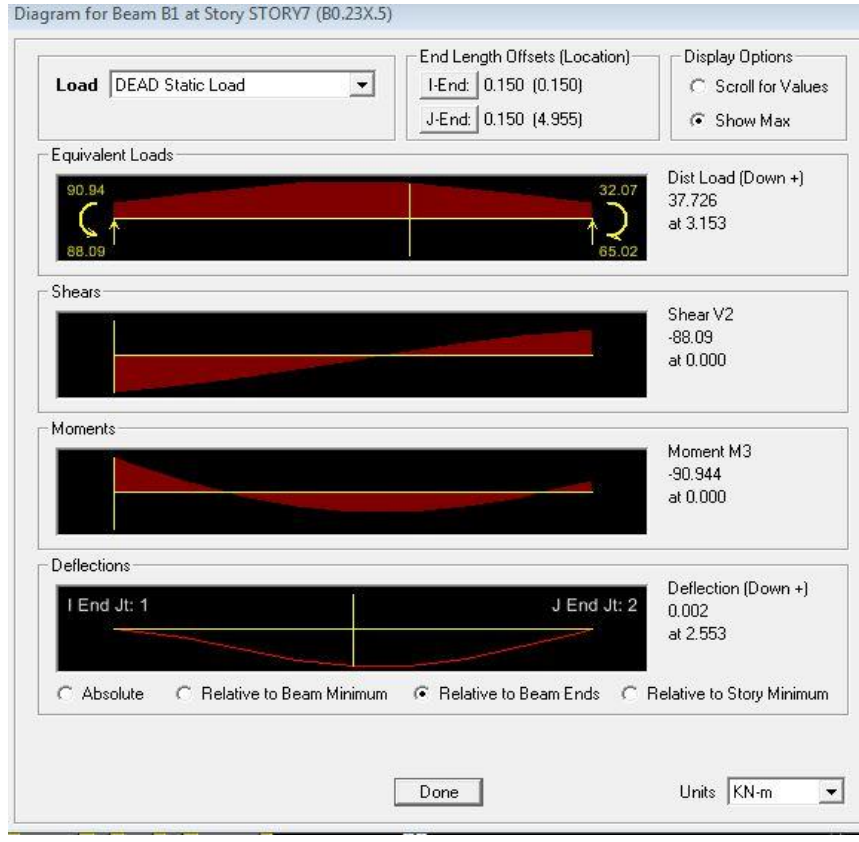

FIG. 3. TYPICAL BEAM BEHAVIOR UNDER DEAD STATIC LOAD
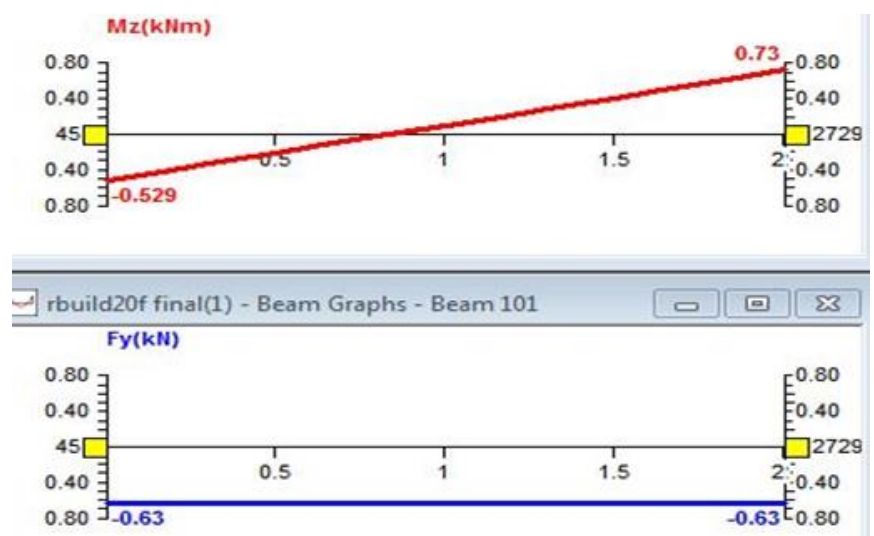

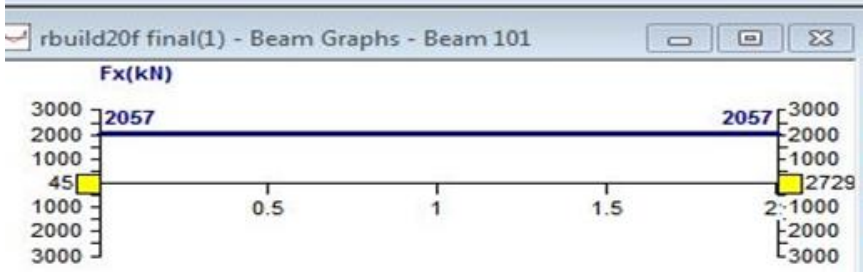

FIG. 4. TYPICAL BEAM BEHAVIOR UNDER LIVE STATIC LOAD

\section{CONCLUDING REMARKS}

A comparative study of response reduction factors, ductility classes, reinforcement detailing provisions, and seismic performance of a ductile $\mathrm{RC}$ frame building designed for four major codes has been performed. The effective stiffness of RC members, procedure to estimate drift, and allowable drift limits are also compared. The comparison of broad ductility classes suggests significant variation in different codes and it is not possible to directly compare the response reduction factors for various ductility classes due to the variation in provisions for reinforcement detailing and capacity design provisions. Most of the codes combine the effect of over strength and ductility in a single response reduction factor, except for NZS 1170.5, which considers the effect of over strength separately through a 'structural performance factor'. Further, only NZS 1170.5 considers the effect of period on response reduction factor. Drift is recognized as an important control parameter by all the codes; however, they differ regarding the effective stiffness of RC members. Further, the procedures to estimate drift and allowable limits on drift also vary. It has been observed that NZS 1170.5 results in the highest design base shear for a given period, for almost all the cases considered in this study. The design base shear as per Eurocode 8 is close to that of NZS 1170.5, while IS 1893 results in the lowest design base shear for a given hazard. The codes also differ significantly on the issue of minimum design base shear, and Eurocode 8 and IS 1893 have no minimum limit on design base shear. Seismic performance of a-story RC frame building designed for different codes has also been compared and it has been observed that the actually provided strength and expected performance of the building is not following the same hierarchy as the design base shear. Further, there is significant variation in the strength capacity of the buildings designed for different codes. The variation in capacity curves may be attributed to differences in design spectra, effective member stiffness values, response reduction or behavior factor, load and material factors, design load combinations, and most importantly, the capping on the design period. All the code designed buildings show Life Safety or better performance level for DBE but show partial/full collapse at MCE. In most of the cases considered in this study, the design was mainly governed by strength while drift was not a governing criteria. However, the inter story drift ratio for most of the code designed buildings is greater than $2.5 \%$ (the highest limit on design drift among all the considered codes) for DBE. In case of MCE, the peak inter story drift ratio reaches up to or exceeds $4 \%$ for most of the codes.

\section{OBSERVATIONS AND REMARKS}

The important observations from the comparison studies are enumerated below:

From the Table 3 and fig. 5 it is clear that the buildings are designed as per the considered seismic codes and the corresponding design codes. The design codes used are ACI 318M-08 (2008), EN1992 (2004), NZS 3101: Part 1 (1995) and IS 1893 (2002), respectively. NZS3101-1995 requires lesser rebar percentage for the chosen beam and column as compared to the other three codes for satisfying the economic criteria of the building (but the least conservative among the above compared codes). Euro Code 2 -1992 also account for column axial load in deciding minimum Rebar percentage from beam bar anchorage view point; however, the requirement on the conservative criteria is more than the NZS Code of Practice. From the fig. 5 , it is well known that the IS 1893-2002 requires the maximum rebar percentage for the chosen beam and column among all three codes, hence is the most conservative as well as uneconomical code of practice to adopt. 


\section{OBSERVATIONS}

From the table 2 and fig. 6 it is obvious that the behavior and expected performance of flexural members of reinforced concrete moment resisting frames against seismic forces can be realized only when the joints are strong enough and having sufficient stiffness to sustain the severe seismic forces set up under lateral loads. A comprehensive table of the issues to be considered in the drift estimation of the present structure has been presented. The design aspects covered by ASCE 318M02, NZS 3101:1995 and EN 1998-1:2003 and IS 1893-02 international codes of practice are appraised and compared. The principles adopted in the estimation of drift by the four codes referred in this paper place high importance in providing for adequate stiffness of longitudinal and transverse bars. The important observations from the comparison studies are enumerated below: ASCE 318M-02 requires smaller story drift than compare to the other three codes, because of less stiffness resistance and the stiffness system is centrally located at exterior frame of $\mathrm{X}$ and $\mathrm{Y}$ direction.

\section{Indian IS 1893-2002}
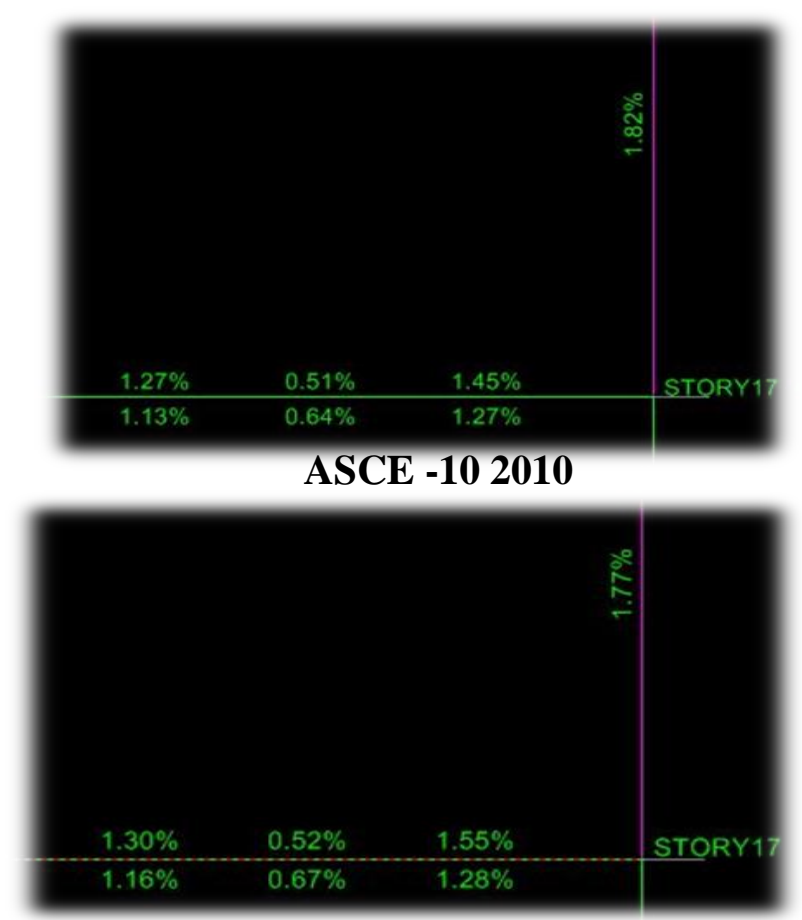

\section{EURo CODE 2 -1992}
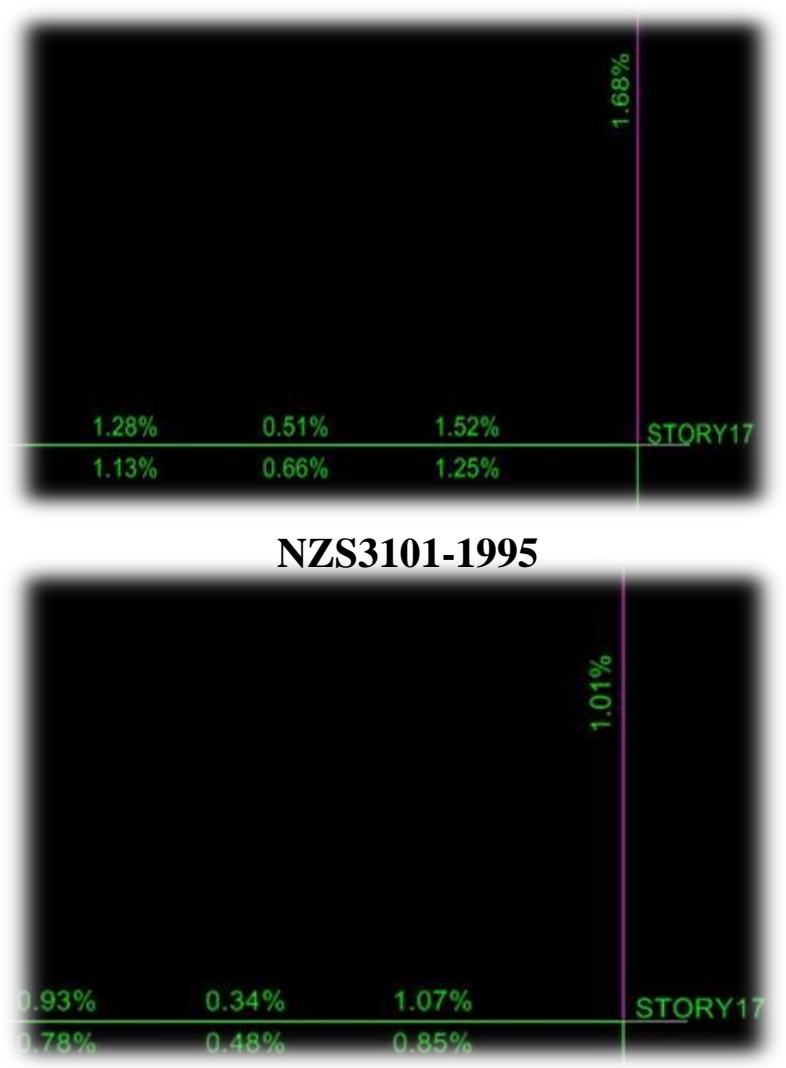

Fig 5 Graphical indication of the rebar percentages obtained from the (Beam $123^{\text {rd }}$ and Column $17^{\text {th }}$ of $17^{\text {th }}$ Storey.)

TABLE 2. DRIFT COMPARISONS AMONG THE CODES

\begin{tabular}{|c|c|c|c|}
\hline \multirow{2}{*}{ Codes } & \multicolumn{2}{|c|}{ Max. Drift in (mm) } & \multirow{2}{*}{$\begin{array}{c}\text { Ranking in } \\
\text { Drift }\end{array}$} \\
\cline { 2 - 3 } & Y direction & X direction & \\
\hline New Zealand3101-95 & 3.32 & 1.65 & Fourth \\
\hline Euro code 2 -1992 & 2.28 & 1.63 & Third \\
\hline ASCE 7-10 2010 & 0.139 & 0.0946 & First \\
\hline IS 1893-02 & 2.25 & 1.24 & Second \\
\hline
\end{tabular}

TABLE 3. REBAR COMPARISONS OF THE CODES

\begin{tabular}{|c|c|c|c|c|c|c|}
\hline Codes & $\begin{array}{c}\text { Rebar } \% \text { at } 1 / 4^{\text {th }} \\
\text { of the beam } 123\end{array}$ & $\begin{array}{c}\text { Rebar } \% \text { at } 1 / 2^{\text {nd }} \\
\text { of the beam } 123\end{array}$ & $\begin{array}{c}\text { Rebar \% at }{ }^{2} 3^{\text {rd }} \\
\text { of the Beam123 }\end{array}$ & $\begin{array}{c}\text { Total Rebar } \\
\% \text { of Beam } \\
123\end{array}$ & $\begin{array}{c}\text { Rebar } \% \text { of } 17^{\text {th }} \\
\text { Column }\end{array}$ & $\begin{array}{c}\text { Ranking } \\
\text { in conservatism }\end{array}$ \\
\hline New Zealand & 1.71 & 0.82 & 1.92 & 4.45 & 1.01 & Fourth \\
\hline Euro & 2.41 & 1.17 & 2.72 & 6.3 & 1.68 & Third \\
\hline ASCE & 2.46 & 1.19 & 2.72 & 6.36 & Second \\
\hline Indian & 2.45 & 1.15 & 2.83 & 6.44 & 1.82 & First \\
\hline
\end{tabular}


Maximum Story Drift According to NZS3101-95

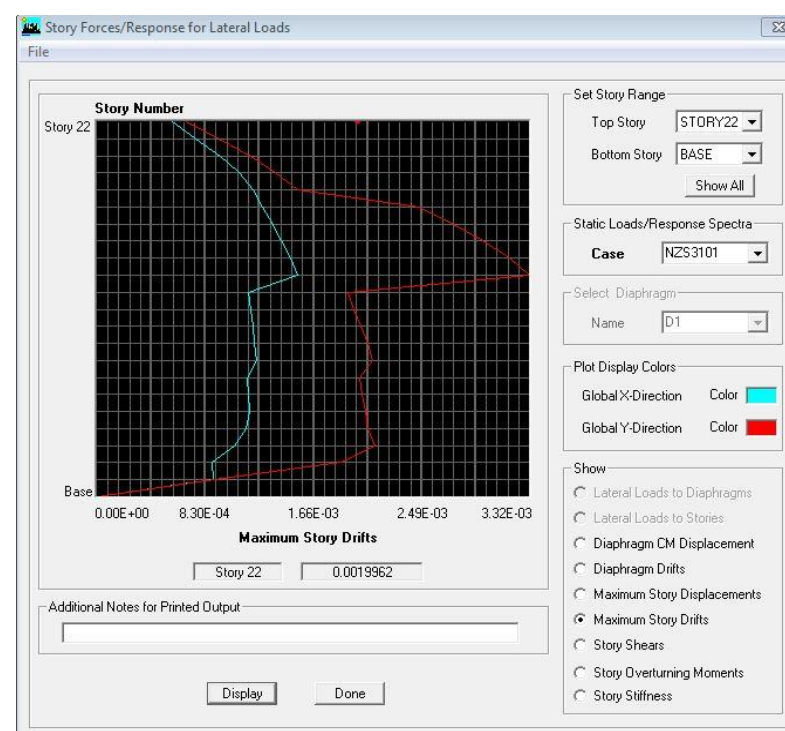

Maximum Story Drift According to IS 1893-2002

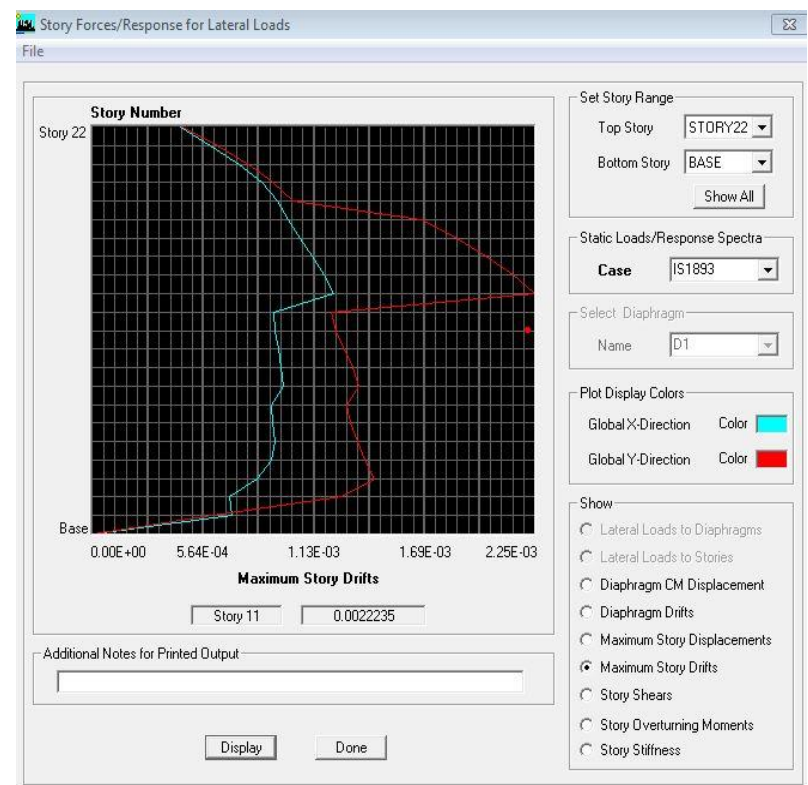

Maximum Story Drift According to ASCE 7-10 2010

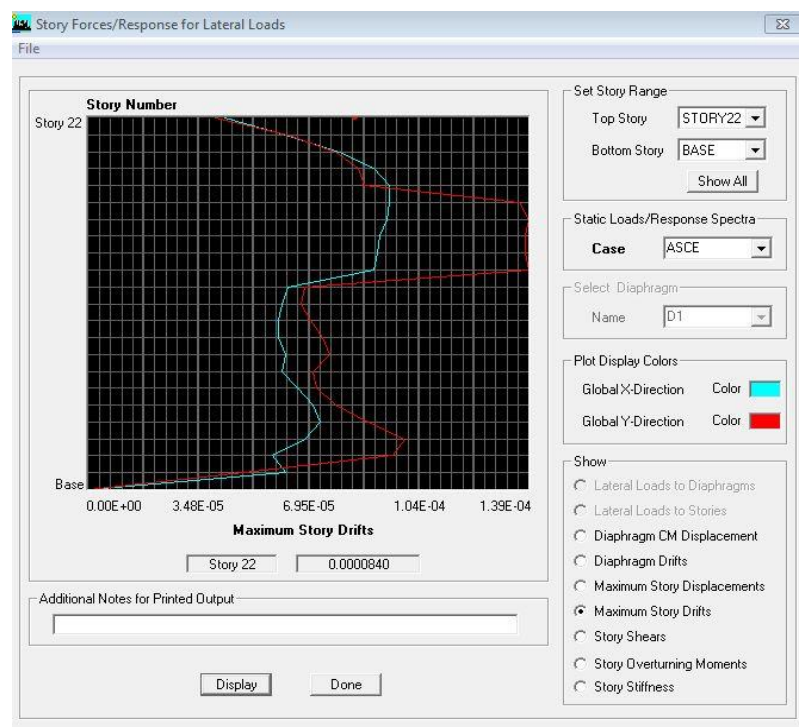

Maximum Story Drift According to EuroCode2 -1992

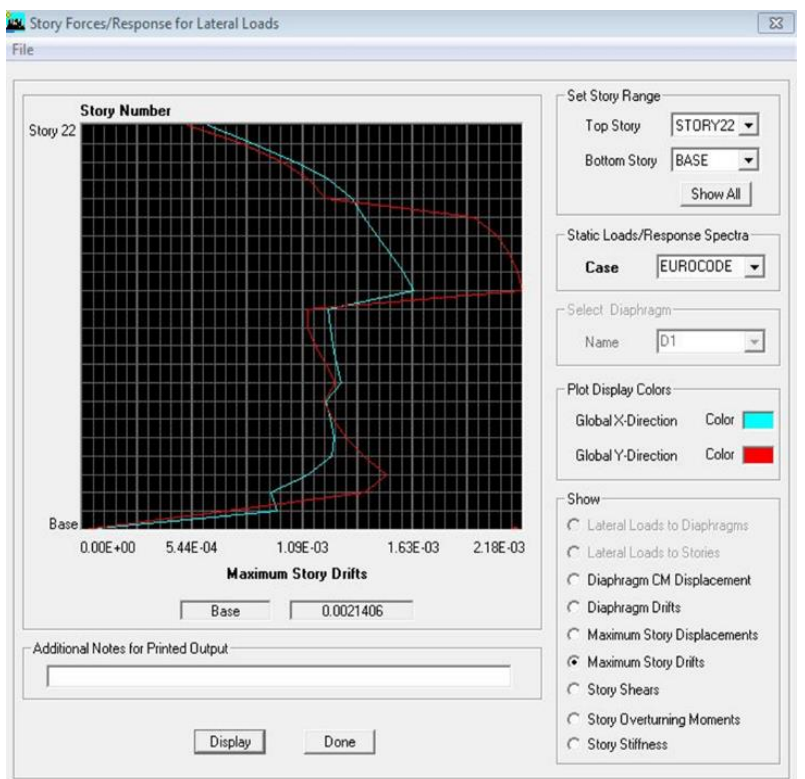

FIG. 6. GRAPHICAL REPRESENTATIONS OF THE STOREY DRIFT RESULTS OBTAINED BY MEANS OF ETABS SOFTWARE 


\section{CONCLUSIONS}

In this study, analysis and design of a residential building has been fulfilled successfully. The structure remodeling in softwares and subsequent dynamic analysis (seismic) of the same using four different codes has been performed thoroughly. The various parameters such as rebar value and drift have been compared for each of the above codes and observations have been made stating the level of conservatism and the probable reasons for the same. Based on our knowledge, this building has adequate strength to resist all the loads and meet its purpose of storage of materials in its life span. Softwares analysis results exhibit that the structure can resist various loads coming on to it. Comparing base to top storey drift in both the longitudinal and transverse direction. A significant amount of increase in the drift has been observed in the New Zealand Code as compared to the ASCE 7-10 2010 and IS $1893-2012$ and Euro Code of practices because of comprising more stiffness behavior.

\section{REFERENCES}

[1] Avadhoot S. Bhosale, Robin Davis, Pradip Sarkar (2018) "Seismic Safety of Vertically Irregular Buildings: Performance of Existing Indicators" Journal of Archit. Engineering- ASCE Vol. 24, No.3: 04018013.

[2] Mohaiminul Haque, Sourav Ray, Amit Chakraborty, Mohammad Elias, Iftekharul Alam (2016) "Seismic Performance Analysis of RCC Multi-Storied Buildings with Plan Irregularity" Science Publishing Group - American Journal of Civil Engineering. Vol. 4, No. 3, 68-73

[3] Zaid Mohammad, Abdul Baqi, Mohammad Arif (2016) "Seismic response of RC framed building resting on hill slopes" Elsevier Ltd - 11th International Symposium on Plasticity and Impact Mechanics, Implast 2016. Procedia Engineering 173 (2017) 1792 -1799 .

[4] "STAAD Pro 2004 - Technical reference manual"- Published by: R.E.I.

[5] Revit Architecture 2009 tutorials - software package.

[6] S.R. Karve and V.L. Shah "Illustrated design of Reinforced concrete Buildings. 